\title{
Macrophage Overexpressing NGAL Ameliorated Kidney Fibrosis in the UUO Mice Model
}

\author{
Roser Guiteras Anna Sola $^{\mathrm{a}}$ Maria Flaquer ${ }^{\mathrm{a}}$ Georgina Hotter ${ }^{\mathrm{b}}$ Joan Torras ${ }^{\mathrm{a}, \mathrm{c}}$ \\ Josep Maria Grinyóa,c Josep Maria Cruzadoa,c \\ aExperimental Nephrology, Department of Ciències Clíniques, Universitat de Barcelona, Institut \\ d'Investigació biomèdica de Bellvitge (IDIBELL), Hospitalet de Llobregat, Barcelona, 'bepartment of \\ Ischemia and Inflammation, Institut d'Investigacions Biomèdiques de Barcelona (IIBB), Barcelona, \\ 'Hospital Universitari de Bellvitge, Hospitalet de Llobregat, Barcelona, Spain
}

\section{Key Words}

Chronic kidney disease $\cdot$ Alternatively activated macrophages $•$ Macrophage plasticity

\begin{abstract}
Background/Aims: Alternatively activated macrophages (AAM) have regenerative and antiinflammatory characteristics. Here, we sought to evaluate whether AAM cell therapy reduces renal inflammation and fibrosis in the unilateral ureteral obstruction (UUO) mice model. Methods: We stabilized macrophages by adenoviral vector NGAL (Neutrophil gelatinaseassociated lipocalin-2) and infused them into UUO mice. To ascertain whether macrophages were capable of reaching the obstructed kidney, macrophages were stained and detected by in vivo cell tracking. Results: We demonstrated that some infused macrophages reached the obstructed kidney and that infusion of macrophages overexpressing NGAL was associated with reduced kidney interstitial fibrosis and inflammation. This therapeutic effect was mainly associated with the phenotype and function preservation of the transferred macrophages isolated from the obstructed kidney. Conclusions: Macrophage plasticity is a major hurdle for achieving macrophage therapy success in chronic nephropathies and could be overcome by transferring lipocalin-2.

\section{Introduction}

Progressive tubulointerstitial fibrosis is the final common pathway for all kidney diseases leading to chronic renal failure [1]. Kidney fibrosis results by ongoing tissue injury and inflammation or if kidney repair is insufficient or suppressed [2]. A common feature in many chronic kidney diseases (CKD) is the renal interstitial inflammatory cell infiltration at early stages $[3,4]$. While inflammation as a whole contributes significantly

R. Guiteras and A. Sola contributed equally to this work. 


\section{Cellular Physiology Cell Physiol Biochem 2017;42:1945-1960

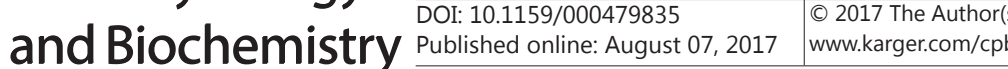 \\ Guiteras et al.: Macrophage Transfer Reduces Chronic Kidney Damage}

to the engagement of fibrogenesis, evidence in recent years also highlights the antifibrotic effects of various lymphocyte and macrophage subsets, providing novel potential avenues for antifibrotic therapies [1]. Macrophages are highly heterogeneous cells that are divided into subpopulations based on their distinct functions. Two well defined phenotypes are commonly referred to as classically activated macrophages (M1), produced by exposure to lipopolysaccharide (LPS) or interferon gamma (IFN- $\gamma$ ) which are pro-inflammatory, and alternatively activated macrophages also called as M2, produced by Th2 cytokines such as IL- 4 and IL-10 [2,5]. M2 macrophages can be further subcategorized into at least three subgroups: M2a induced by IL-4 and/or IL-13 (wound healing macrophages), M2b induced by immune complexes and regulatory macrophages known as M2c (anti-inflammatory macrophages) [6-8]. However, in vitro classification of macrophages does not necessarily reflect their true phenotypes in vivo; hence, a newly suggested classification closely reflects phenotypes of in vivo macrophages, and has been defined as pro-inflammatory, anti-inflammatory, fibrotic and fibrolytic [2]. Nevertheless, these proposed macrophage phenotypes deserve to be well defined.

A pathogenic role of macrophages in kidney disease has been demonstrated by depletion of kidney macrophages by liposomal clodronate (LC) in ischemia reperfusion injury (IRI) and unilateral ureteral obstruction (UUO) models [8,9]. Nevertheless, there is increasing evidence showing that macrophages also play a key healing role during the reparative phase after kidney injury $[10,11]$. Some studies revealed that depletion of macrophages at the time of injury phase (M1 predominantly) and during repair phase (when M2 are predominant) attenuated kidney injury and delayed kidney repair [2]. Further studies suggested that macrophages change their phenotype in response to signals from the local kidney milieu although the mechanisms by which they are polarized are not well understood [12, 13]. Ex vivo programmed macrophages displaying anti-inflammatory or reparative phenotype have been used as a macrophage cell therapy in distinct injured kidney mice models including IRI, lupus nephritis and Adriamycin nephropathy $[12,14,15]$ with discordant results, suggesting that phenotypic stability of transferred cells in vivo is critical to achieve therapeutic success.

In a murine model of diabetic kidney disease, we have previously demonstrated that hepatocyte growth factor (HGF) gene therapy increases the presence of bone marrow-derived M2 macrophages, which seem to contribute to the renal tissue repair and regeneration [16]. However, it is unclear what the role of "M2" macrophages are in UUO renal fibrosis, though some descriptive studies would suggest that "M2" macrophages are associated with fibrosis in the UUO context [9]. Although most studies showed association of M2 infiltration with renal fibrosis, the information regarding adoptive transfer of M2 in vivo is scarce. Therefore, in the present study we sought to examine the therapeutic effects of alternatively activated bone marrow-derived macrophages ( $\phi$-IL-4/IL-13) cell therapy in the UUO mice model, a well-established model of renal fibrosis. As we did not observe any therapeutic effect, we further characterized the phenotype and the functional plasticity of infused $\phi$-IL-4/IL13 macrophages isolated from the obstructed kidney, showing that the lack of effect was associated with transition to M1-like phenotype. Finally, we provided evidence that this limitation could be overcome by the infusion of genetically modified and stable $\phi$-NGAL macrophages.

\section{Materials and Methods}

\section{Macrophage cell culture}

$\Phi$-IL-4/IL-13 isolation and culture. Primary cultures of murine macrophages were obtained from bone marrow of C57bl/6J mice purified by CD11b+ negative selection (EasySep, Stemcell technologies, Grenoble, France). Bone marrow-derived monocytes were matured in DMEM/F12 + GlutaMAX (Gibco, Waltham, USA) medium supplemented with $10 \%$ fetal bovine serum, $1 \%$ penicillin and $20 \mathrm{ng} / \mathrm{ml}$ macrophage colonystimulating factor (M-CSF) (ProSpec, East Brunswick, NJ, USA) and cultured the last 3 days with $10 \mathrm{ng} / \mathrm{ml}$ of IL-4 and IL-13 (Invitrogen, CA, USA) to become M2 macrophages. All cells were maintained at $37^{\circ} \mathrm{C}$ in a 


\section{Cellular Physiology Cell Physiol Biochem 2017;42:1945-1960 \begin{tabular}{l|l|l} 
DOI: 10.1159/000479835 & $\begin{array}{l}\text { O } 2017 \text { The Author(s). Published by S. Karger AG, Basel } \\
\text { www.karger.com/cpb }\end{array}$
\end{tabular}}

Guiteras et al.: Macrophage Transfer Reduces Chronic Kidney Damage

$5 \% \mathrm{CO}_{2}$ incubator. Cells were harvested and the macrophage phenotype and purity were assessed by FACS analysis.

Culture and transduction of $\Phi-N G A L$ and $\Phi-\beta G A L$

Mice RAW 264.7 macrophages were transduced with either adenoviral vector NGAL ( $\phi$-NGAL) or the control vector $\beta$-galactosidase ( $\phi$ - $\beta$ GAL) as previously described by the group [17]. Adenoviral vectors were applied in order to transduce macrophages ex vivo. The adenoviral vector carrying cDNA encoding recombinant NGAL and $\beta$-GAL were elaborated, amplified, and purified by ViraQuest, Inc (North Liberty, IA, USA). Transfected cells were incubated for 24 hours at $37^{\circ} \mathrm{C}$ in a $\mathrm{CO}_{2}$ incubator.

\section{Flow cytometry analysis}

To analyze the purity of cultured macrophages for the cell therapy, cells were stained with PEconjugated anti-mouse F4/80 (eBioscience, San Diego, CA, USA), APC-conjugated anti-mouse CD11b (BD Bioscience, San Jose, CA, USA), FITC-conjugated anti-mouse mannose receptor (CD206) and CD86 both from Biolegend (San Diego, CA, USA). Flow cytometry was performed using a FACS CANTO II cytometer (BD Bioscience, San Jose, CA, USA) and data was acquired and analyzed using FACS DIVA software.

Animals

Eight-weeks-old C57bl/6J male mice were purchased from Janvier (Laval, France). All procedures followed the Guidelines of the European Community Committee on Care and Use of Laboratory Animals and Good Laboratory Practice. Mice were monitored daily for body weight and were housed at constant temperature with a $12 \mathrm{~h}$-light/12 h-dark cycle. They were given water and standard chow ad libitum.

\section{Surgical technique and experimental design}

UUO surgery was performed under continuous inhaled isofluorane anesthesia (2\%). Mice were placed on a thermostatically controlled operating table. The left flank was opened through a small incision and whereby the bowel gently displaced to one side and covered with sterile saline-soaked gauze; the left ureter was exposed and ligated with 6-0 silk suture (Ethicon, Edinburgh, UK). The bowel was then laid back in place and muscle and skin were then closed with sterile surgical of 4-0 nylon (B. Braun, Melsungen, Germany). For the UUO time-course study tissue were harvested on day $1,3,5,7,9,11,13$, and $15(n=3)$.

UUO mice were divided into the following groups according to the killed day ( $\mathrm{n}=7$ each group): UUO day 9, UUO+ $\Phi$-IL-4/IL-13 day 9, UUO+ $\phi$-NGAL day 9, UUO+ $\phi-\beta$ GAL day 9, UUO day 15 , UUO+ $\Phi-I L-4 / I L-13$ day 15 and UUO $+\phi-N G A L$ day 15 , UUO $+\phi-\beta$ GAL day 15 . Wild type mice and contralateral kidneys were used as controls. For the cell therapy, one million $\left(1 \times 10^{6}\right)$ of $\Phi$-IL-4/IL-13, $\phi$-NGAL or $\phi-\beta G A L$ macrophages were infused into UUO mice via the tail vein at day 7 after the UUO surgery.

\section{Macrophage in vivo tracking}

In order to assess whether adaptive transfer of exogenous macrophages reached obstructed kidneys, a macrophage tracking in vivo study was performed. Macrophages were cultured and then stained with a red fluorescent membrane label Vivotrack680 (Vertex, Barcelona, Spain) according to manufacturer's instruction. One million $\left(1 \times 10^{6}\right)$ labeled macrophages were injected into mice by a single tail-vein injection at day 7 after UUO. Mice were killed $48 \mathrm{~h}$ after macrophage injection (day 9 after UUO surgery) and were assayed and quantified $(n=3)$. Living Image ${ }^{\circledR}$ Software was used to analyze the images.

\section{Renal macrophages phenotypic characterization}

To assess the macrophage renal cell sorting and the further phenotypic characterization, labeled macrophages were injected at day 7 after UUO surgery and mice were killed $48 \mathrm{~h}$ after macrophage cell therapy. Kidneys were carefully removed and cut into 1-2 $\mathrm{mm}^{3}$ pieces, excluding any adjoining renal fat. Slices were incubated in $1 \mathrm{ml}$ of $2 \mathrm{mg} / \mathrm{ml}$ Collagenase I (Sigma, Steinheim, Germany) for $30 \mathrm{~min}$ at $37^{\circ} \mathrm{C}$. Gently cell suspension was filtered in BD cell strainer $(70 \mu \mathrm{m})$ and re-suspended in $2 \mathrm{ml}$ of DMEM medium with $20 \%$ of FBS. Suspension was centrifuged at $1500 \mathrm{rpm}$ for $5 \mathrm{~min}$. Pellet was re-suspended with $1 \mathrm{ml}$ of Lysis Buffer and suspension was allowed to settle briefly ( $5 \mathrm{~min}$ ). $1 \mathrm{ml}$ of DMEM medium with $20 \%$ of FBS was added to stop the lysis buffer reaction and then centrifuged again at $1500 \mathrm{rpm}$ for $5 \mathrm{~min}$. Supernatant was decanted and $2 \mathrm{ml}$ of PBS was added for counting cells to estimate the number of total cells in the suspension. 


\section{Cellular Physiology Cell Physiol Biochem 2017;42:1945-1960

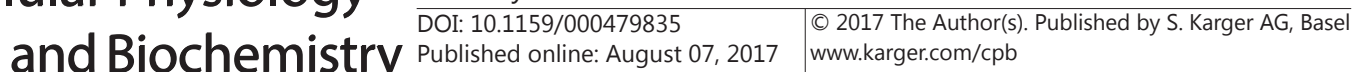

Guiteras et al.: Macrophage Transfer Reduces Chronic Kidney Damage

To analyze both exogenous and endogenous macrophages phenotype in the UUO treated mice, a cell sorting experiment with a MoFlo Astrios Cell Sorter (Beckman Coulter, Pasadena, CA, USA) was performed. Firstly, two parameters were used to select macrophages from the entire kidney (both obstructed and contralateral): positive VivoTrack680 fluorescence cells, which are the macrophages from the cell therapy, and the negative Vivotrack680 cells, which are the endogenous cells. Exogenous macrophages (Vivotrack680 positive) were labeled with FITC-conjugated anti-mouse mannose receptor (CD206) (M2 marker) and CD86 (PE) (M1 marker) antibodies to analyze their phenotype, whereas endogenous macrophages were detected with anti-mouse F4/80 PE-Cy7 (Affymetrix eBioscience, CA, USA) and anti-mouse CD11b APC-Cy7 (BD Bioscience, San Jose, CA, USA) antibodies from the entire Vivotrack680 negative population. Detection of M1 macrophages with anti-mouse CD86 PE (BD Bioscience) and M2 macrophages with FITC-conjugated anti-mouse mannose receptor (CD206) (Biolegend San Diego, CA, USA) was evaluated for endogenous macrophages. After labeling, samples were re-suspended in $500 \mu \mathrm{l}$ of FACS buffer (PBS with 2mM EDTA and $0.5 \mathrm{mM}$ BSA) and filtered through a $40 \mu \mathrm{M}$ micron filter to remove any clamps or aggregates prior to analysis.

Optical microscopy, immunohistochemical, immunofluorescence and confocal studies

After UUO, mouse kidneys were removed under anesthesia and rapidly decapsulated and chopped into 2-3 mm pieces. Renal slices were fixed in 10\% (vol./vol.) formalin and embedded in paraffin. All pieces contained both cortex and medulla. Histological cross sections of $3 \mu \mathrm{m}$ thickness were stained with Haematoxylin and eosin (H\&E), Sirius Red, Fibronectin and anti- $\alpha$-smooth muscle actin ( $\alpha$-SMA) for optical microscopy assessment. Fibronectin (1:500, Abcam, Madrid, Spain) and $\alpha$-SMA (1:100, Thermo Scientific, CA, USA) were stained as described previously [16].

Fibronectin, Sirius Red and $\alpha$-SMA staining were quantified using Image J software in each nonoverlapping cortical field from the cortical region. To evaluate the degree of renal injury, a magnification of x200 was assessed to quantify histological sections. Points within brown and red areas were considered positives. Scores from 5 fields per kidney section were averaged and mean scores were quantified. Values are obtained as relative stained area (\%). Pathological evaluation of interstitial fibrosis and tubular atrophy (IFTA) was also assessed following Banff criteria [18] and graded as follows: 0, no damage; 1, Mild interstitial fibrosis and tubular atrophy ( $<25 \%$ of cortical area); 2 , Moderate interstitial fibrosis and tubular atrophy (26-50\% of cortical area) and 3, Severe interstitial fibrosis and tubular atrophy/loss ( $>50 \%$ of cortical area).

Confocal studies (using a Leica TCS-SL confocal spectral microscope, Mannheim, Germany) were performed in a blinded manner on paraffin-embedded renal tissues. Anti-mouse F4/80 (1:50, LabClinics, Barcelona, Spain) and double immunolabeling of F4/80 and anti-mannose-receptor (CD206) (1:50, Abcam) antibodies were analyzed using immunofluorescence. Slides were stained with: F4/80 to assess macrophage infiltration and mannose receptor for the M2 macrophage subpopulation. Nuclei were stained blue with DRAQ5. F4/80-positive cells located in the interstitial area were analyzed in 20 random fields in each sample and assessed using Image J software. Values are obtained as relative stained area (\%). CD206 positive macrophages were numerically quantified of the entire sample. Alexa Fluor488 (green) and Alexa Fluor555 (red) were used as secondary antibodies (Invitrogen, CA, USA).

\section{Quantitative real-time PCR}

RNA was extracted from kidney with PureLink RNA Mini Kit (Invitrogen, CA, USA) as previously described [16]. A total amount of 400 ng RNA was used to perform the reverse transcription using a HighCapacity cDNA Reverse Transcription Kit (Applied Biosystems, Warrington, UK). Thermal cycling conditions were $10 \mathrm{~min}$ at $25^{\circ} \mathrm{C}, 120 \mathrm{~min}$ at $37^{\circ} \mathrm{C}, 5 \mathrm{~min}$ at $85^{\circ} \mathrm{C}$ and finally held at $4^{\circ} \mathrm{C}$. The mRNA expression levels of TGF- 1 1, MMP-9, CD40, MCP-1, IL-10, N-GAL, iNOS, E-cadherin, Aquaporin-2, Megalin, Heme Oxygenase-1 (HO-1) and Wnt7b were quantified by TaqMan real-time PCR (ABI Prism 7700, Applied Biosystems, Waltham, USA) using the comparative 2-[delta][delta]ct method (Applied Biosystems).

\section{Functional characterization of macrophages isolated from the UUO kidney}

Sorted macrophages were collected and RNA was extracted as described previously in the quantitative real-time PCR paragraph. RNA was necessarily pre-amplified before the real-time reverse transcriptase PCR was performed. Renal macrophage expression levels of TGF- $\beta 1$, MMP-9, IL-10, Wnt7b, HO-1 and TNF- $\alpha$ were quantified by TaqMan real-time PCR (ABI Prism 7700, Applied Biosystems, Waltham). 


\section{Cellular Physiology Cell Physiol Biochem 2017;42:1945-1960 \begin{tabular}{ll|l}
\cline { 2 - 3 } DOI: 10.1159/000479835 & (c) 2017 The Author(s). Published by S. Karger AG, Basel
\end{tabular} and Biochemistry Published online: August 07, 2017 www.karger.com/cpb

Statistical analysis

All data are reported as mean \pm SE. Group means were compared with either the Student's $t$ test or ANOVA for parametric values, or the Mann-Whitney $U$ test or Krustal-Wallis test for non-parametric values. $\mathrm{P} \leq 0.05$ was considered to be statistically significant. All statistical analyzes were carried out using StatView software.

\section{Results}

Renal macrophage infiltration correlates with interstitial fibrosis development in the UUO model

First of all, we confirmed that renal macrophage infiltration correlates with interstitial fibrosis development in the UUO model. Fibrosis was assessed and scored using Fibronectin and Sirius Red staining (Fig. 1B-E). As observed in Fig. 1, an increasing number of interstitial macrophages infiltrating the obstructed kidney were detected (Fig. 1A). Macrophage infiltration began at day 3 and increased exponentially after day 7. Therefore, we selected day 7 as appropriate timing for macrophage cell therapy administration in order to reduce fibrosis and inflammation. More detailed information regarding the evolution of kidney fibrosis in the UUO model is provided in Fig. 2. As expected, pro-inflammatory and pro-fibrotic cytokines such as TGF- $\beta 1$, MCP-1, CD40 and MMP-9 were upregulated in the obstructed kidney.

\section{Adoptive macrophage cell transfer reaches the obstructed kidney}

Then, to ascertain whether the infused macrophages reached the obstructed tissue, we performed in vivo cell tracking and specific assessment in several organs using Vivotrack680

Fig. 1. Renal macrophage infiltration correlates with interstitial fibrosis. (A) Representative confocal microscopy images of immunofluorescence showing red staining for macrophages F4/80 and blue staining for nuclei DRAQ5. Original magnification, $\times 400$. (B) Representative photomicrographs of Fibronectin in the obstructed kidney. Original magnification, $\times 200$. (C) Graphical correlation of both macrophage infiltration and interstitial. (D) Representative photomicrographs of Sirius Red in the obstructed kidney. Original magnification, $\times 200$. (E) Sirius Red quantification. Data are represented as mean \pm S.E. ( $n=3$ in each group).

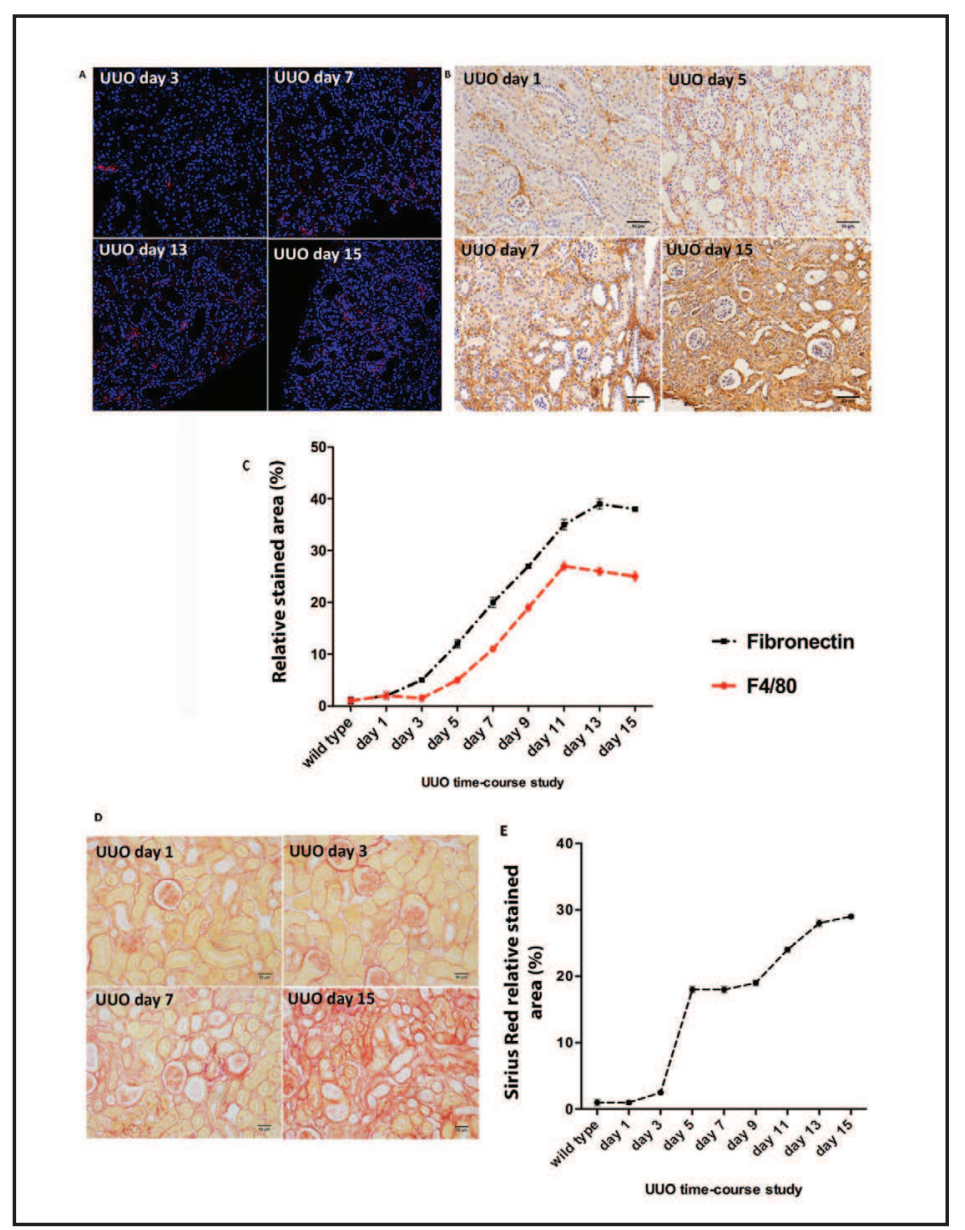




\section{Cellular Physiology Cell Physiol Biochem 2017;42:1945-1960 \begin{tabular}{ll|l} 
DOI: 10.1159/000479835 & O 2017 The Author(s). Published by S. Karger AG, Basel \\
\hline
\end{tabular} \\ Guiteras et al.: Macrophage Transfer Reduces Chronic Kidney Damage}

Fig. 2. Gene expression profile of MMP-9, TGF- $\beta 1$, MCP- 1 and CD40 in the obstructed kidney. mRNA kidney levels were measured in the obstructed kidney at different time points after UUO surgery and analysed by real-time reverse transcriptionpolymerase chain reaction (RTPCR) and real-time qPCR. Data are normalized to levels in GAP$\mathrm{DH}$. Values are means $\pm \mathrm{SE}$. ${ }^{*} \mathrm{P} \leq$ 0.05 vs wild type.
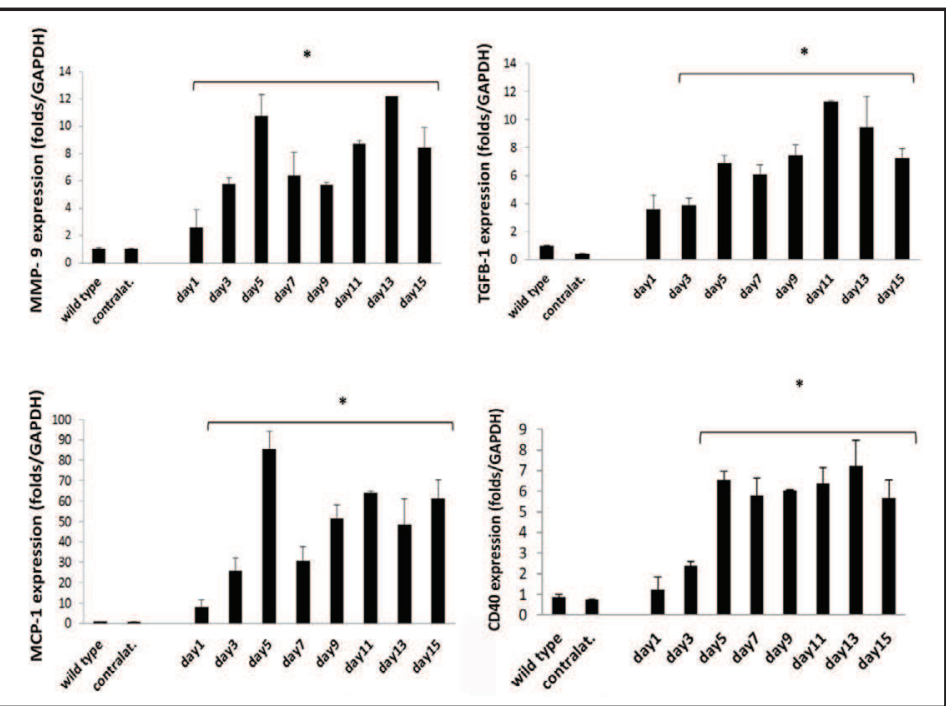

Fig. 3. In vivo tracking of infused macrophages. (A) Animals were analyzed in IVIS-Lumina2000 machine $24 \mathrm{~h}$ and $48 \mathrm{~h}$ after macrophage cell therapy. Fluorescence intensity corresponds with increasing amount of cells. (B) Although several organs were quantified, fluorescent labelled macrophages were mainly retained in liver $48 \mathrm{~h}$ after infusion. (C) Graphical quantification of the fluorescence intensity in several organs. (D) Detailed picture of the detection of the fluorescent labelled macrophages retained in obstructed (L) and contralateral kidney (R) after the therapy. (E) Graphical quantification of the fluorescence intensity in contralateral and obstructed kidney after the cell therapy. The images are representative for one of the two types of cell therapy included in the study, the same results were obtained for both therapies (n $=3$ each one).

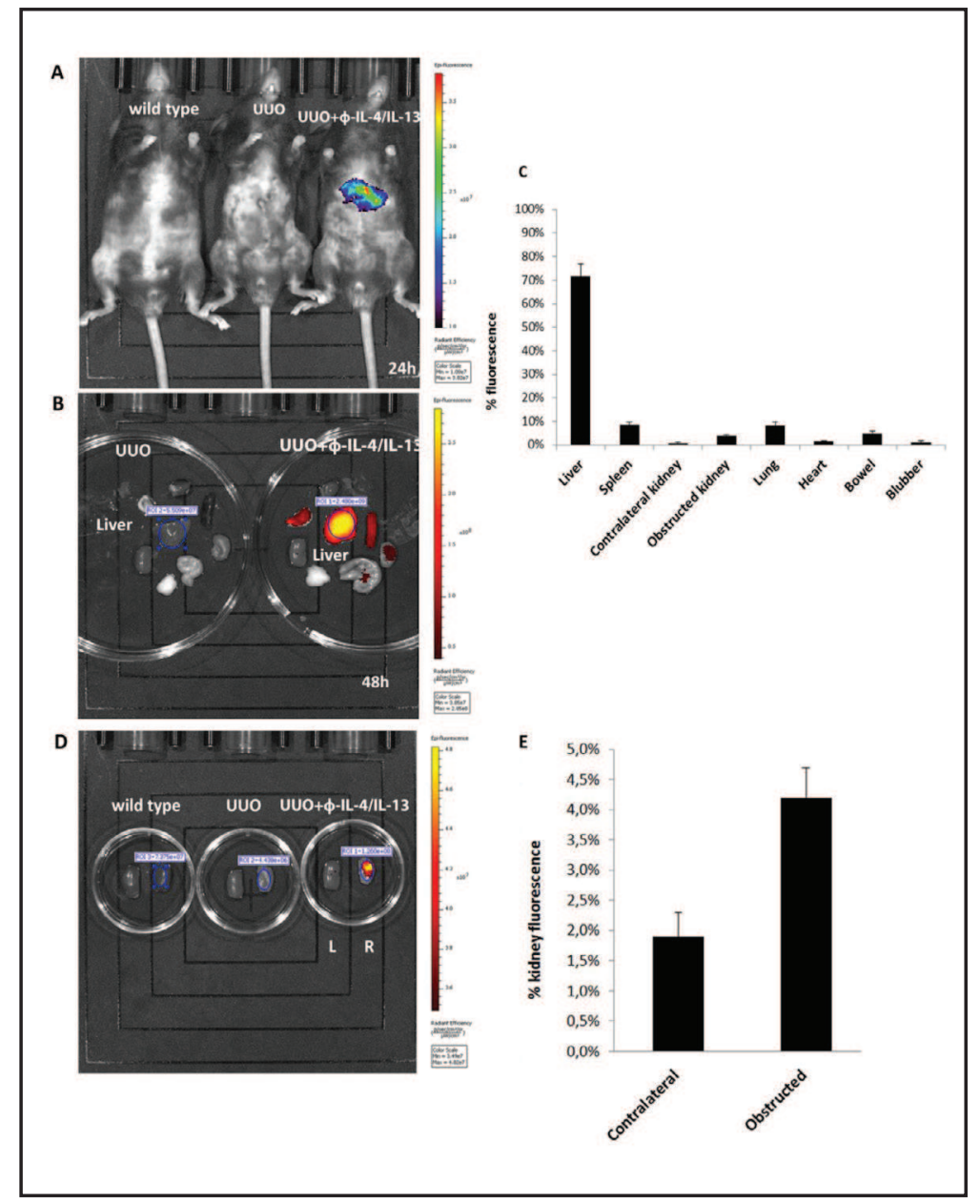

NIR fluorescent agent (Fig. 3). The macrophages used for the in vivo cell tracking yielded a $>96 \%$ of double F4-80 and CD11b-positive. Further characterization confirmed their alternative M2 phenotype, showing almost 100\% of CD206 positive marker (M2 phenotype) and CD86 negative (M1 marker) (Fig. 4A). Our results indicated that those infused macrophages were higher in the obstructed kidney than in the contralateral non-obstructed kidney (Fig. 3D-E) probably due to the inflammatory recruitment signals present in the 


\section{Cellular Physiology Cell Physiol Biochem 2017;42:1945-1960 and Biochemistry \begin{tabular}{c|l}
\hline DOI: 10.1159/000479835 2017 The Author(s). Published by S. Karger AG, Basel \\
Publisned
\end{tabular}

Fig. 4. Macrophage phenotype analysis and gene expression profile previous to infusion. Macrophages were cultured and F4/80, CD11b, CD86 and CD206 expression were analysed by FACS CANTO cytometry. (A) Cultured $\phi$-IL-4/IL-13 macrophages were supplemented with $20 \mathrm{ng} / \mathrm{ml}$ $\mathrm{M}-\mathrm{CSF}$ and $10 \mathrm{ng} / \mathrm{ml} \mathrm{IL-4}$ and IL-13 the last 3 days in vitro and displayed no CD86 and high CD206 expression. $\phi$-NGAL were likewise analysed showing high expression of CD206 and no CD86. In contrast, $\phi$ - $\beta$ GAL showed neither CD86 nor CD206 expression. (B) The mRNA expression of HO-1, IL-10, Wnt7b, TNF- $\alpha$, N-GAL, Mannose Receptor (MR) CD206, TGF- $\beta 1$ and MMP-9, were measured by qPCR in fresh cultured $\phi$-IL-4/IL-13,
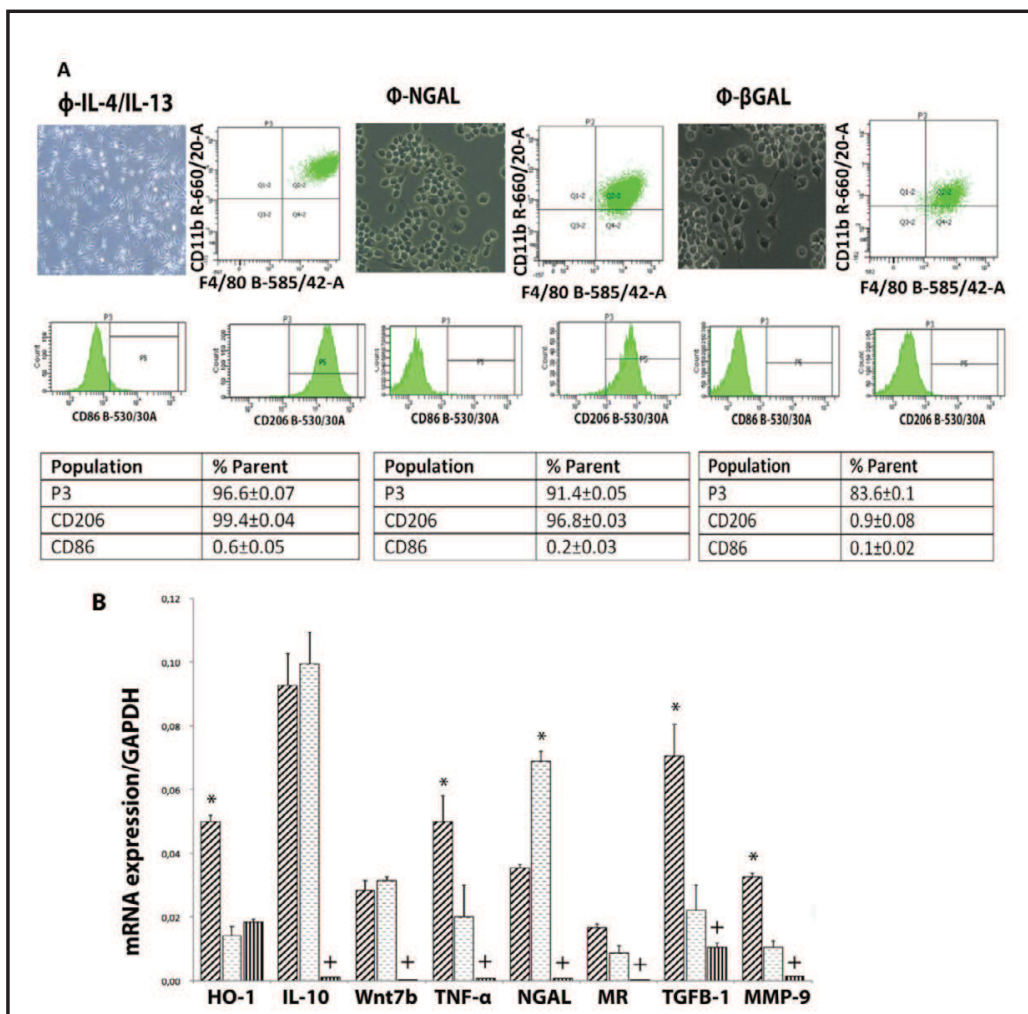
$\phi$-NGAL and $\phi$ - $\beta$ GAL previously to infusion. Data are normalized to levels by GAPDH. Values are means \pm SE. $* \mathrm{P} \leq 0.05 \Phi$-IL-4/IL-13 vs $\phi$-NGAL; $+\mathrm{P} \leq 0.05 \phi$-NGAL vs $\phi$ - $\beta$-GAL. $\mathrm{n}=3$ in each group.

damaged tissue. Moreover, our results showed that the liver was the main organ retaining exogenous macrophages (Fig. 3B-C), as previously described by other authors[14, 19, 20]. Once the detection of the infused macrophages in the kidney was confirmed, we next isolated them by cell sorting two days after the infusion to analyze their phenotype and function.

Phenotypic characterization of the $\Phi$ IL-4/IL-13 and $\phi$-NGAL exogenous macrophages isolated from the obstructed kidney

In both therapies, around $2 \%$ of infused macrophages were detected in the obstructed kidney and $0.01 \%$ in the contralateral kidney. In the case of $\Phi-\mathrm{IL}-4 / \mathrm{IL}-13$ therapy, Vivotrack680 positive cells comprised $2.19 \pm 0.32 \%$ of the entire viable cells detected in the whole obstructed kidney (Fig. 5A), which displayed $44.69 \pm 3.06 \%$ of CD86+ (M1 marker), $2.13 \pm 0.31 \%$ of CD206+ (M2 marker) and $53.2 \pm 2.71 \%$ of double positive (both M1 and M2 markers). On the other hand, in the case of $\phi$-NGAL therapy, Vivotrack680 positive macrophages were the $1.71 \pm 0.22 \%$ (Fig. 5A), which displayed $30.45 \pm 4.05 \%$ of CD86+ (M1 marker), $4.91 \pm 0.53 \%$ of CD206+ (M2 marker) and $64.64 \pm 4.21 \%$ of double positive. Therefore, a higher M1-percentage of exogenous macrophages was observed in $\Phi$-IL-4/IL13 therapy, whereas the M2 proportion was nearly double in $\phi$-NGAL (Fig. 5B). Regarding endogenous renal macrophages, they represented the $25 \pm 0.7 \%$ of all UUO kidney cells in both therapies, with $15.34 \pm 0.32 \%$ of M1, $6.34 \pm 1.58 \%$ of M2 and $78.32 \pm 1.65 \%$ of double staining in $\Phi$-IL-4/IL-13 and $26.34 \pm 0.23 \%$ of M1, $6.79 \pm 0.24 \%$ of M2 and $66.88 \pm 0.28 \%$ of double staining in $\phi$-NGAL (Fig. 5C).

In the contralateral kidney, the amount of exogenous $(0.01 \%)$ and endogenous $(0.63 \pm$ $0.06 \%$ in $\Phi$-IL-4/IL-13 and $0.72 \pm 0.01 \%$ in $\phi$-NGAL) macrophages was too low to take their characterization into account (Fig. 5A-D). 

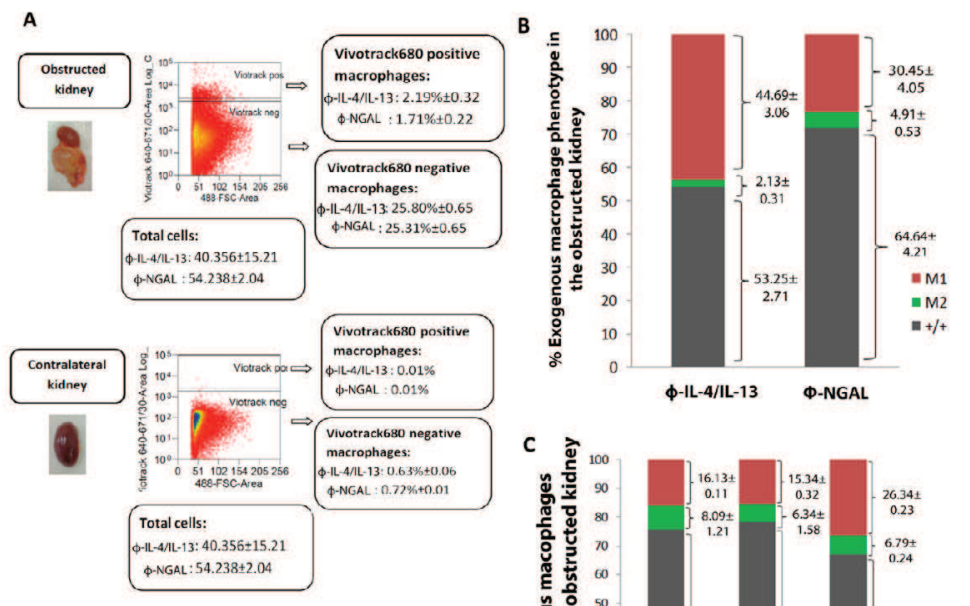

D 1

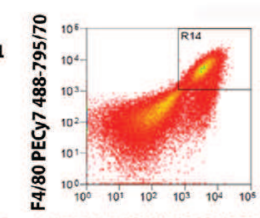

D2
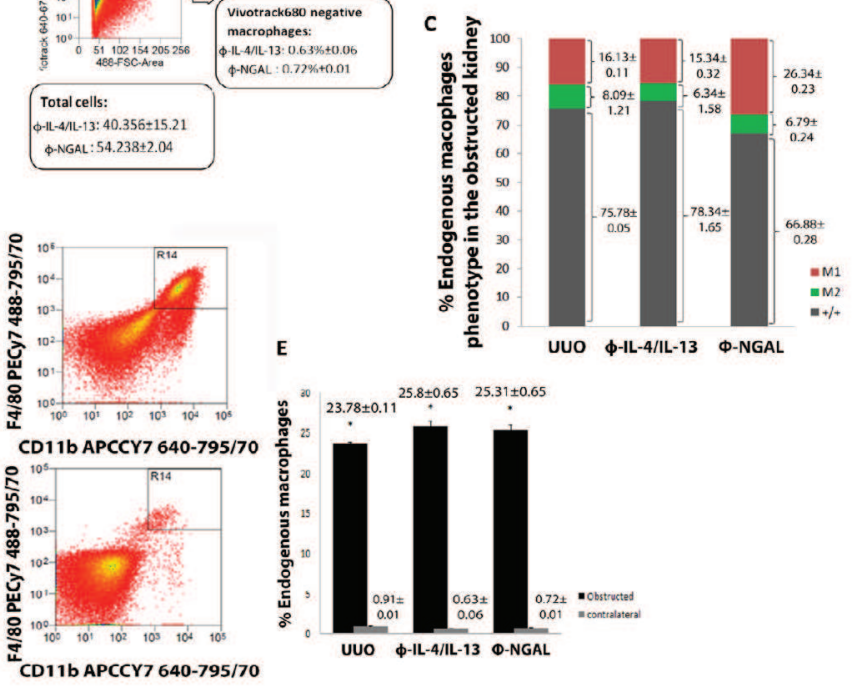

Fig. 5. Phenotype identification after therapy revealed the maintenance of the M2 phenotype in transformed macrophages. (A) Positive (exogenous) and negative (endogenous) Vivotrack680 macrophage evaluation of obstructed and contralateral kidneys 2 days after therapy ( 9 days after UUO surgery). Barely 2\% of infused macrophages were detected in the obstructed kidney and $0.01 \%$ in the contralateral kidney. Vivotrack680 positive selection was marked with CD86 and CD206 for macrophage phenotype, while Vivotrack680 negative selection was marked with F4/80 and CD11b for macrophages identification and then CD86 and CD206 for phenotype. (B) Representation of the exogenous macrophage phenotype after $\phi$-IL-4/IL-13 and $\phi$-NGAL therapies in the obstructed kidney illustrating the capacity of $\phi$-NGAL in preserving M2 phenotype after the therapy. (C) Graphical representation of endogenous macrophage phenotype comparison between control UUO, $\phi$-IL-4/IL-13 and $\phi$-NGAL mice. (D) Representative image of endogenous macrophages from obstructed (D1) and from contralateral kidney (D2) in mice with or without therapy and (E) graphical representation of the corresponding percentages. Obstructed vs contralateral, ${ }^{*} P \leq 0.05, \mathrm{n}=3$ in each group.

Functional characterization of infused $\Phi I L-4 / I L-13$ and $\phi-N G A L$ isolated from the obstructed kidney

We then measured the expression of several pro-reparative and pro-fibrotic genes in the isolated endogenous and exogenous macrophages. Gene expression of pro-fibrotic as well as pro-reparative markers from endogenous and exogenous macrophages is shown in Fig. 6. Exogenous macrophages from $\Phi$-IL-4/IL-13 treated mice expressed high levels of TGF- $\beta 1$ and less MMP-9. By contrast, $\phi$-NGAL showed higher levels of Wnt7b and NGAL, whereas HO-1 expression was not modified.

Endogenous macrophages from obstructed kidneys without cell therapy exhibited high mRNA levels of MMP-9, TGF- $\beta 1$ and TNF- $\alpha$ and reduced levels of NGAL, Wnt7b and HO-1. Cell therapy treatment induced a decrease of MMP-9, TGF- $\beta 1$ and TNF- $\alpha$, and an increase 


\section{Cellular Physiology Cell Physiol Biochem 2017;42:1945-1960 \begin{tabular}{ll|l} 
and Biochemistry & $\begin{array}{l}\text { DOI: } 10.1159 / 000479835 \\
\text { Published onlne: August 07, } 2017\end{array}$ & $\begin{array}{l}\text { O 2017 The Author(s). Published by S. Karger AG, Basel } \\
\text { www.karger.com/cpb }\end{array}$ \\
\cline { 2 - 3 }
\end{tabular} \\ Guiteras et al.: Macrophage Transfer Reduces Chronic Kidney Damage}

Fig. 6. Functional plasticity of infused macrophages. Gene expression profile of both exogenous and endogenous macrophages isolated after the therapy. Comparing the expression levels of exogenous macrophages, $\quad \phi$-IL-4/ IL-13 expressed high levels of TGF- $\beta 1$ in contrast to $\phi$-NGAL macrophages. Moreover, $\phi$-NGAL displayed high levels of NGAL expression. Additionally, the repair-signaling molecule Wnt7b was higher expressed in $\phi$-NGAL macrophages whereas the HO-1 expression was not modified. Macrophage from obstructed organs without cell therapy exhibit high mRNA levels of MMP-9, TGF- $\beta 1$ and TNF- $\alpha$, otherwise reduced levels of NGAL, Wnt7b and HO-1. ANOVA test; the values represent the mean \pm SE. ${ }^{*} P \leq 0.05$ vs endogenous macrophages from non-treated animals. $+P \leq$ 0.05 vs exogenous macrophages among therapies. $\mathrm{n}$ $=3$ in each group.
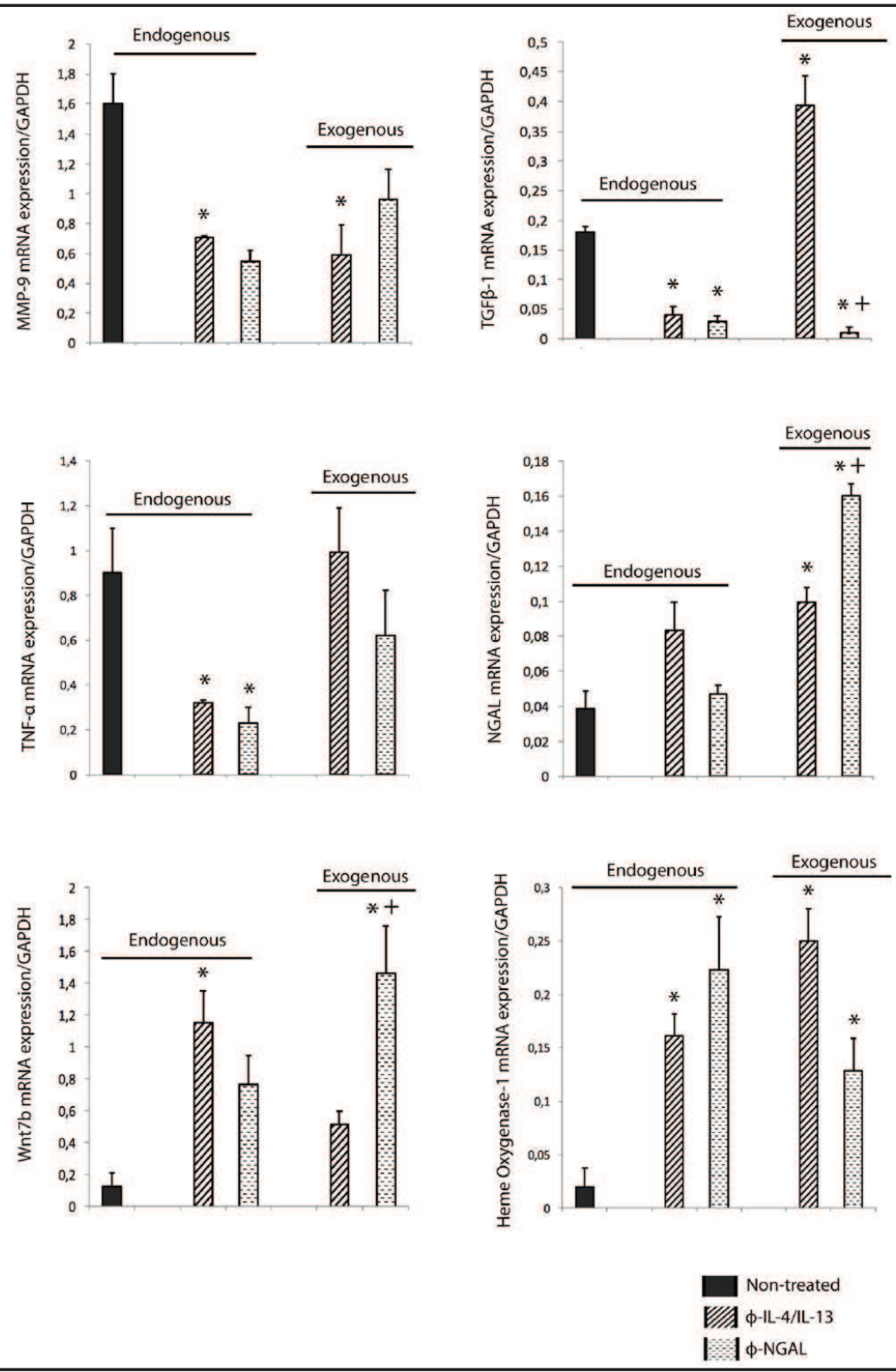

of Wnt7b and HO-1 gene expression in the endogenous macrophages. Figure 4B shows the gene expression profile of the macrophages prepared for the therapy at baseline, that is, before infusion.

Only genetically stabilized macrophage cell therapy reduced interstitial fibrosis and inflammation in the UUO model

First, we found that $\Phi$-IL-4/IL-13 cell therapy did not improve the severity of IFTA, neither fibrosis, evaluated by Fibronectin and Sirius Red stain, or $\alpha$-SMA renal expression at day 9. In contrast, $\phi$-NGAL treated mice showed reduced kidney IFTA, reduced fibrosis and decreased $\alpha$-SMA expression in comparison to the UUO group (Fig. 7). $\Phi$ - $\beta$ GAL treated mice showed no amelioration of IFTA, fibrosis and $\alpha$-SMA expression compared to UUO nontreated mice both at day 9 and 15 (Fig. 8). Similar results at day 15 for $\Phi-$ IL-4/IL-13 and $\phi$-NGAL treated mice are shown in Fig. 9.

Then, as showed in Table 1, we observed that $\phi$-NGAL cell therapy was associated with a significant reduction of some pro-inflammatory and pro-fibrotic renal genes as well as with a higher expression of some genes related to kidney epithelial integrity. 


\section{Cellular Physiology Cell Physiol Biochem 2017;42:1945-1960 \begin{tabular}{ll|l} 
and Biochemistry Published onlne: August 07, 2017 & $\begin{array}{l}\text { @ 2017 The Author(s). Published by S. Karger AG, Basel } \\
\text { www.karger.com/cpb }\end{array}$ \\
\hline
\end{tabular}}

Fig. 7. Tubulo-interstitial damage and interstitial fibrosis evaluation of the obstructed kidneys. (A) Representative images of Haematoxylin\&Eosin (H\&E), Fibronectin, $\alpha$-smooth muscle actin ( $\alpha$-SMA) and Sirius Red staining of control UUO, $\phi$-IL-4 / IL-13 and $\phi$-NGAL treated mice at day 9 after kidney obstruction. Original magnification, $\times 200$. (B) Graphical quantification of $\mathrm{H} \& \mathrm{E}$, Fibronectin, $\alpha-S M A$ and Sirius Red from each group. Mann-Whitney test; the values represent the mean \pm SE. $* P \leq$ 0.05 vs UUO day 9 .

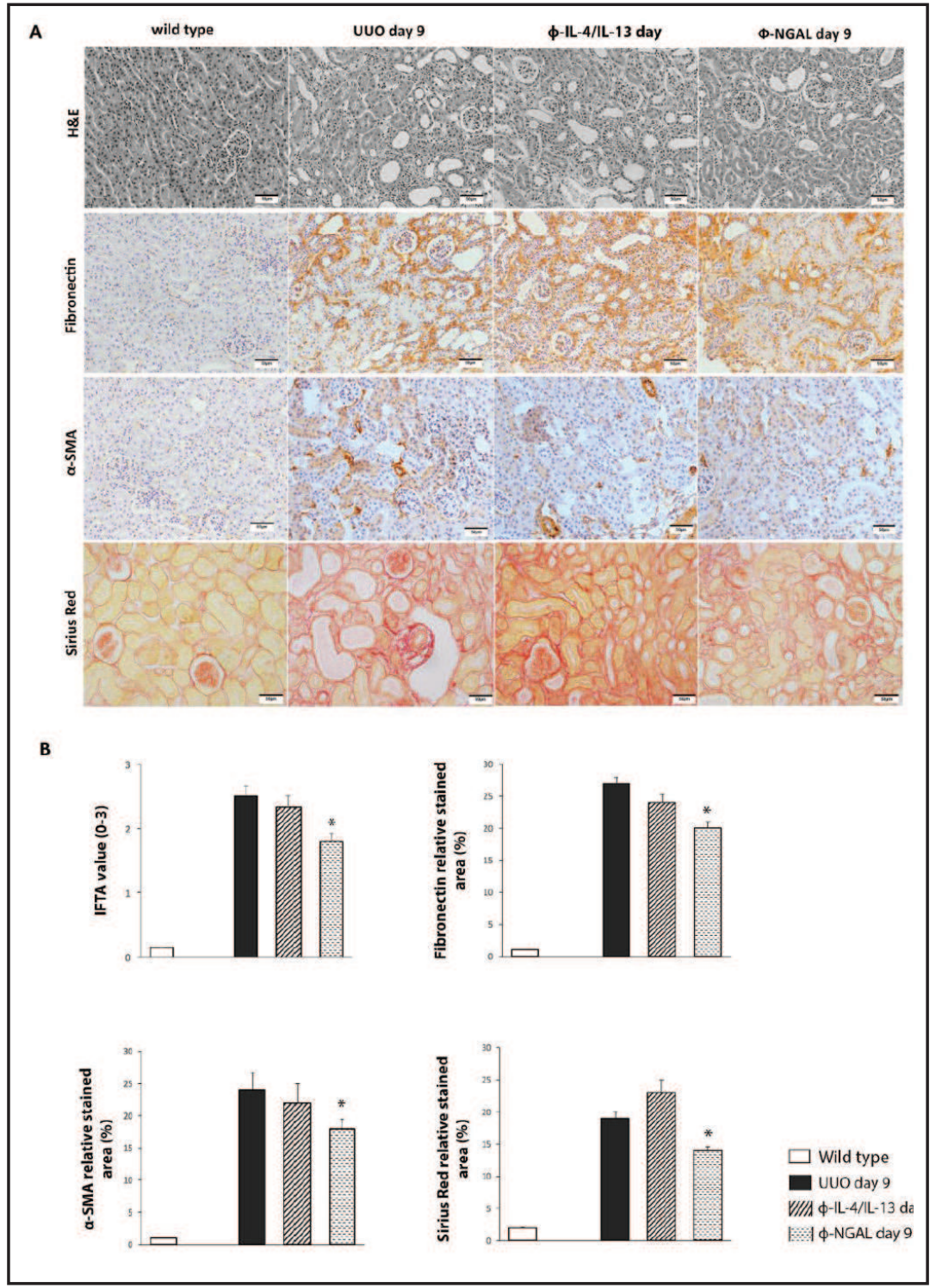

Finally, we examined the amount of M2 macrophages (mannose receptor) in the obstructed kidney (Fig. 10). We found no differences among UUO control mice and $\Phi$-IL-4/ IL-13 mice. Interestingly, we observed a high number of positive CD206 macrophages in the $\phi$-NGAL treated animals.

\section{Discussion}

Regenerative medicine is in preclinical development in nephrology. Among potential strategies [21-23], macrophage cell-therapy provides promising but discordant results [12, $14,15,19,20,24]$. Macrophage precursors can be isolated from the bone marrow or spleen, alternatively activated in vitro and then infused to test their effect on acute and chronic kidney disease models. In humans, bone marrow and blood cells are commonly used as cellular therapy [12]. Cell therapy using autologous macrophages seems safer than some stem cell based therapies, at least in terms of tumor development risk [25] and immunogenicity [26]. Interestingly, although M2 macrophages are required for the kidney repair after injury, their fate or long-term effect still remains uncertain [27]. Recently, Harris and Wang [2] proposed that in chronic kidney disease M1 macrophages increase in kidney tissue whereas M2 


\section{Cellular Physiology Cell Physiol Biochem 2017;42:1945-1960

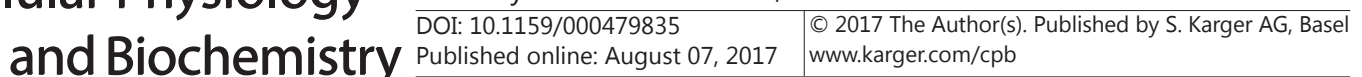

Fig. 8. Tubulo-interstitial damage and interstitial fibrosis evaluation of the obstructed kidneys from $\phi-\beta G A L$ treated mice. Representative images of H\&E, Fibronectin, $\alpha$-SMA and Sirius Red staining of wild type and $\phi$ - $\beta$ GAL treated mice at day 9 and 15 after kidney obstruction. Mann-Whitney test; the values represent the mean \pm SE from each group.

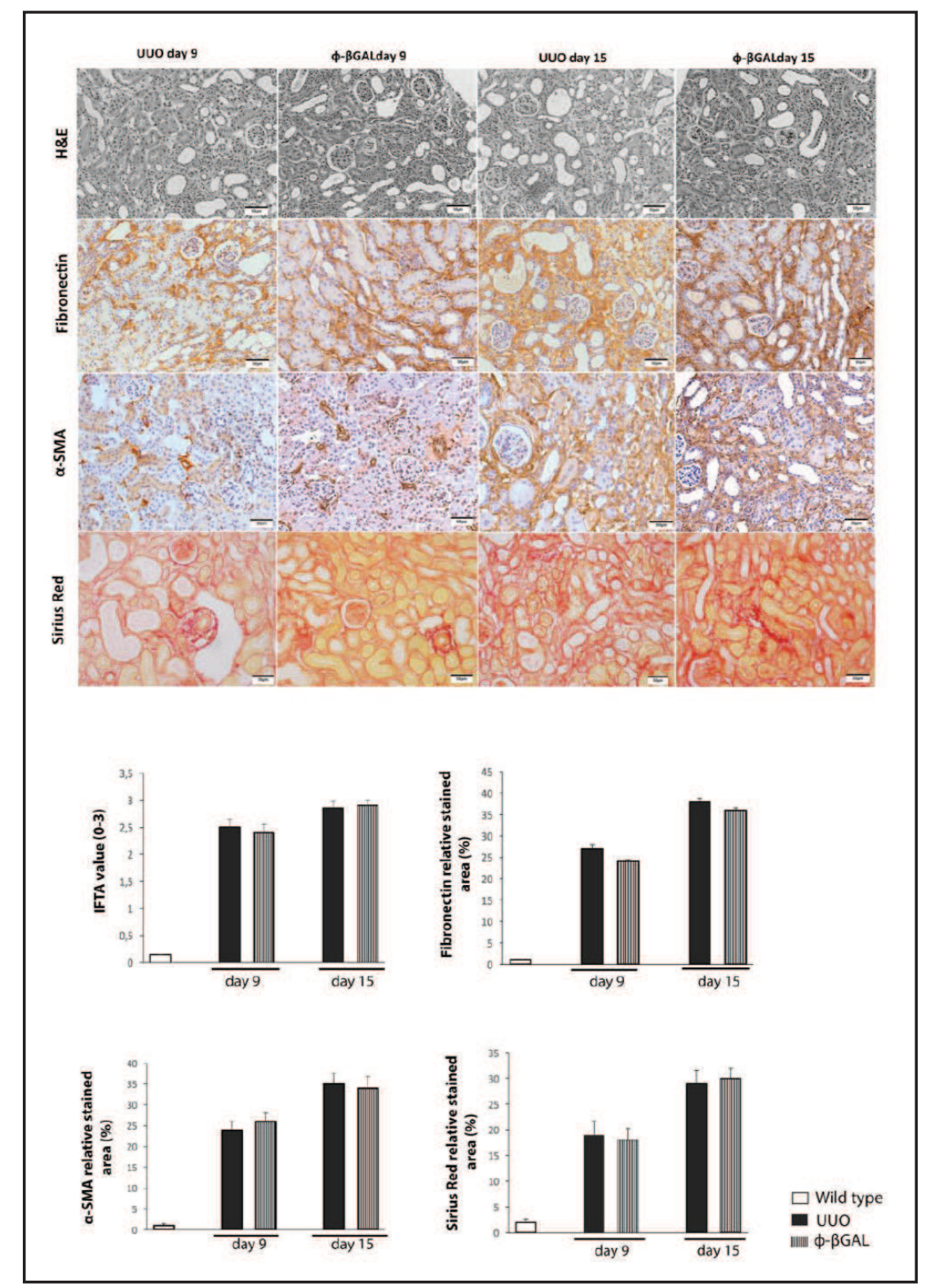

Table 1. Gene expression profile of the obstructed kidney in treated and non-treated animals. For all qRT-PCR experiments, data are normalized to levels in GAPDH. Data represent mean $\pm \mathrm{SE}$. from each group Mann-Whitney test *P $\leq 0.05 \phi$-IL-4/ IL13 d 9 and $\phi$-NGALd9 vs UUOd9; †P $\leq 0.05$ $\Phi$-IL-4/IL-13d15 and $\phi$-NGALd15 vs UUOd15

\begin{tabular}{|c|c|c|c|c|c|c|c|}
\hline \multirow[b]{2}{*}{ Pro-/Anti-inflammatory } & \multicolumn{7}{|c|}{ Group } \\
\hline & $\begin{array}{l}\text { wild } \\
\text { type }\end{array}$ & UUOd9 & $\begin{array}{l}\begin{array}{l}\Phi-I L-4 / I L- \\
13 \mathrm{~d} 9\end{array} \\
\end{array}$ & Ф-NGAL9 & UUOd15 & $\begin{array}{l}\text { Ф-IL-4/IL- } \\
13 \mathrm{~d} 15\end{array}$ & Ф-NGALd15 \\
\hline MCP-1/CCL-2 & $0.88 \pm 0.1$ & $41.44 \pm 2.4$ & $39.45 \pm 4.3$ & $33.59 \pm 2.2^{*}$ & $50.36 \pm 5.4$ & $31.07 \pm 1.6 \dagger$ & $34 \pm 2.6 \dagger$ \\
\hline CD40 & $0.87 \pm 0.1$ & $7.35 \pm 0.3$ & $6.59 \pm 0.4$ & $5.98 \pm 0.4^{*}$ & $6.77 \pm 0.3$ & $8.48 \pm 0.1 \dagger$ & $6.67 \pm 0.4$ \\
\hline iNOS & $1.2 \pm 0.2$ & $13.42 \pm 5.1$ & $8.17 \pm 3.0$ & $9.98 \pm 2.6$ & $13.66 \pm 1.2$ & $20.13 \pm 7.1$ & $11.51 \pm 3.9$ \\
\hline IL-10 & $1.1 \pm 0.0$ & $60.6 \pm 10.2$ & $51 \pm 8.9$ & $72.5 \pm 9.8$ & $69.15 \pm 10.1$ & $88.92 \pm 10.8$ & $57.65 \pm 6.1$ \\
\hline \multicolumn{8}{|l|}{ Fibrosis } \\
\hline TGF $\beta-1$ & $0.81 \pm 0.2$ & $4.2 \pm 0.2$ & $2.89 \pm 0.5^{*}$ & $2.81 \pm 0.1^{*}$ & $4.7 \pm 0.6$ & $4.0 \pm 0.5$ & $3.1 \pm 0.7 \dagger$ \\
\hline MMP-9 & $1.04 \pm 0.1$ & $14.54 \pm 3.0$ & $9.22 \pm 0.8$ & $10.49 \pm 2.8$ & $12.21 \pm 2.2$ & $17.25 \pm 4.5$ & $6.5 \pm 0.6 \dagger$ \\
\hline \multicolumn{8}{|l|}{$\begin{array}{l}\text { Repair/Epithelial } \\
\text { integrity }\end{array}$} \\
\hline Megalin & $1.30 \pm 0.2$ & $0.61 \pm 0.1$ & $0.49 \pm 0.1$ & $0.56 \pm 0.0$ & $0.48 \pm 0.2$ & $0.31 \pm 0.1$ & $0.45 \pm 0.2$ \\
\hline E-cadherin & $1.2 \pm 0.3$ & $2.84 \pm 0.8$ & $3.94 \pm 1.1$ & $4.17 \pm 1.3^{*}$ & $3.74 \pm 1.1$ & $3.92 \pm 0.8$ & $5.37 \pm 1.2 \dagger$ \\
\hline Aquaporin-2 & $1.1 \pm 0.0$ & $4.40 \pm 1.0$ & $4.69 \pm 2.7$ & $9.09 \pm 2.1^{*}$ & $1.70 \pm 0.3$ & $1.39 \pm 0.1$ & $8.07 \pm 3.0+$ \\
\hline
\end{tabular}




\section{Cellular Physiology Cell Physiol Biochem 2017;42:1945-1960 \begin{tabular}{ll|l} 
and Biochemistry & Dublished online: August 07, 2017 & $\begin{array}{l}\text { @ } 2017 \text { The Author(s). Published by S. Karger AG, Basel } \\
\text { www.karger.com/cpb }\end{array}$ \\
\hline
\end{tabular}}

Fig. 9. Tubulo-interstitial damage and interstitial fibrosis evaluation of the obstructed kidneys at day 15 . Representative images of H\&E, Fibronectin, $\alpha$-smooth muscle actin ( $\alpha$-SMA) and Sirius Red staining of control UUO, $\quad \phi$-IL-4/IL-13 and $\phi$-NGAL treated mice at day 15 after kidney obstruction. Mann-Whitney test; the values represent the mean \pm SE from each group. ${ }^{*} P \leq 0.05$ vs. UUO day 15.

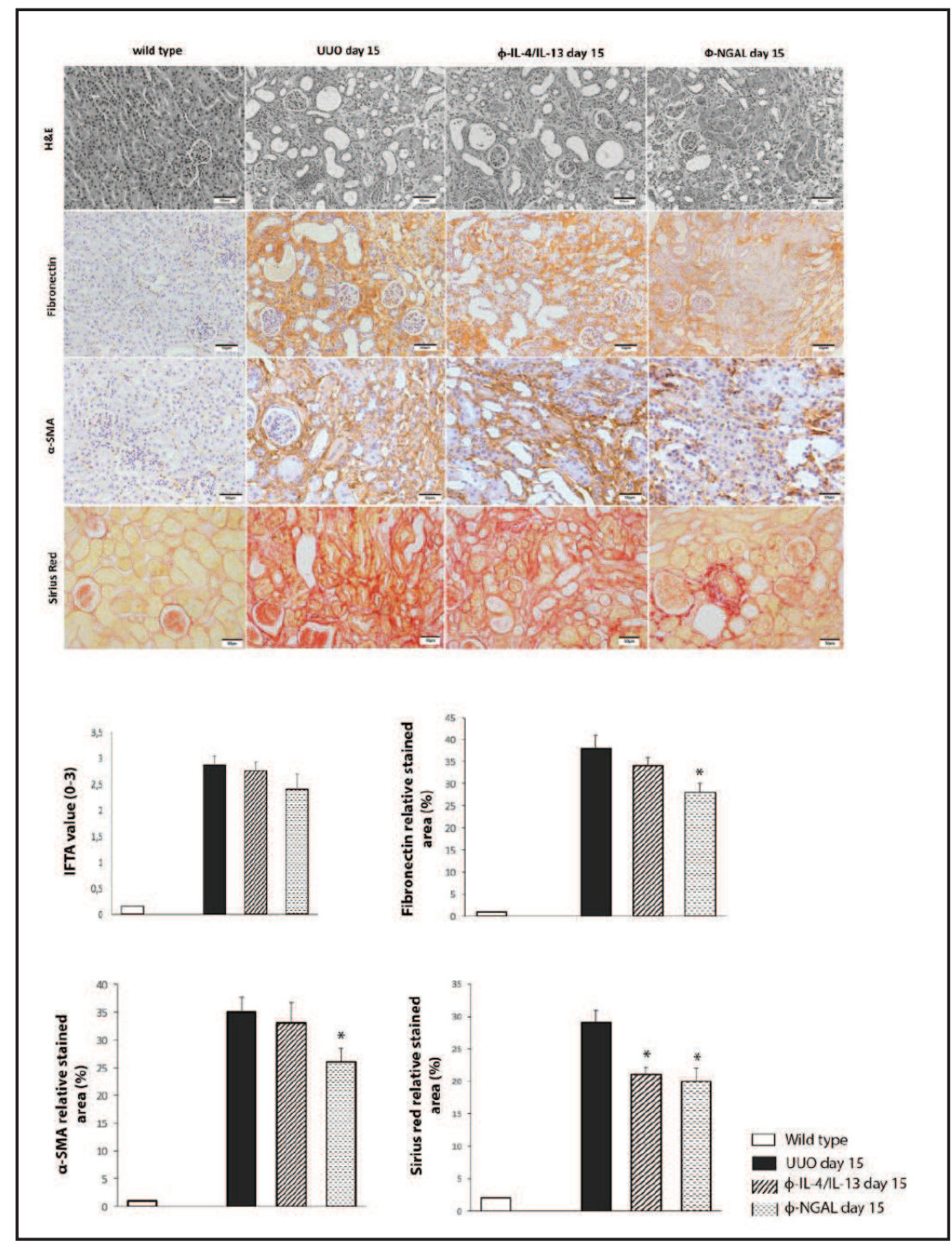

macrophages coexist in small numbers or are absent due to persistent inflammatory kidney milieu. Therefore, there is a rationale to test whether M2-macrophage cell therapy is able to induce regression of the persistent inflammation and fibrosis in chronic kidney disease.

We demonstrate that macrophages from cell therapy, although mainly retained in the liver, are capable of reaching the damaged kidney parenchyma. Our findings are in agreement with two studies performed on murine Adriamycin nephropathy [12,14]. Therefore, infused macrophages could exert their protective effect on the UUO kidney directly, by a paracrine mechanism or both [26].

Nevertheless, we found that, between the two tested therapies, $\Phi \cdot I L-4 /$ IL-13 macrophage cell-therapy was unable to induce any kidney protective effect. In fact, histological damage and the expression of some pro-inflammatory and pro-fibrotic genes in the obstructed kidney were similar in treated and non-treated groups. Cao et al. [12] reported similar findings by $\Phi-I L-4 / I L-13$ macrophage cell therapy on murine Adriamycin nephropathy. Moreover, we found that the proportion of M2 macrophages in the UUO kidney was the same in $\Phi$-IL-4/IL13 and non-treated control groups. Taking together, these results suggest that $\Phi$-IL-4/IL-13 macrophages could switch their phenotype depending on the kidney environment [2]. On the other hand, we performed a cell therapy group of genetically modified stabilized cell line that produce SIP-dependent neutrophil gelatinase-associated lipocalin (NGAL/Lcn-2) [28], trying to overcome the plasticity of $\Phi$-IL-4/IL-13 macrophages. Previously, we have reported 


\section{Cellular Physiology Cell Physiol Biochem 2017;42:1945-1960 \begin{tabular}{l|l|l} 
and Biochemistry Published online: August 07, 2017 & $\begin{array}{l}\text { ( ) 2017 The Author(s). Published by S. Karger AG, Basel } \\
\text { www.karger.com/cpb }\end{array}$ \\
\hline
\end{tabular} \\ Guiteras et al.: Macrophage Transfer Reduces Chronic Kidney Damage}

Fig. 10. Immunofluorescence of M2 macrophages in the obstructed kidney. (A) Quantification ratio for $\mathrm{F} 4 / 80+$ (positive stained area $\%$ ) and Mannose receptor CD206 (total number of positive cells). Representative images of immunofluorescence for F4/80+ (red staining), M2 marker CD206 (green staining) and nuclei (blue staining) in the UUO non-treated obstructed kidney (B) and $\phi$-NGAL treated mice (C). Original magnification, $\mathrm{x} 400$. Mann-Whitney test. Error bars show means \pm SE from each group. ${ }^{*} P \leq 0.05$ vs UUO day 15 .

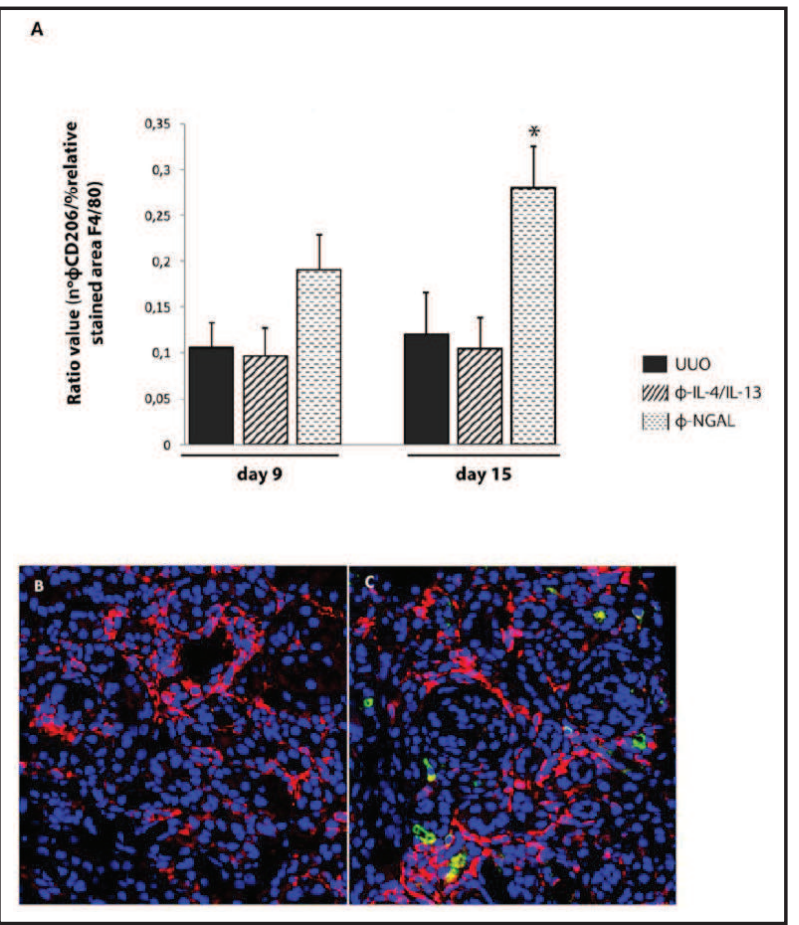

that $\phi$-NGAL macrophages, due to their IL-10 over-expression, were effective during the inflammatory phase of renal ischemia and reperfusion injury [28]. With this macrophage therapy, we found that kidney pro-inflammatory genes such as MCP-1 and CD40 as well as the kidney fibrosis markers TGF $\beta-1$ and MMP-9, were significantly reduced. Furthermore, after $\phi$-NGAL infusion, the proportion of M2 macrophages in the UUO kidney was higher than after $\Phi-\mathrm{IL}-4 / \mathrm{IL}-13$ therapy. These results suggest that $\phi$-NGAL macrophages could preserve their phenotype when they reach the damaged kidney.

As there is lack of evidence about this macrophage phenotypic switch in vivo [2], we sought then to provide new knowledge by isolating the infused macrophages from the obstructed kidneys to analyze their phenotype and functional activity in comparison with baseline macrophage cell therapy and resident kidney macrophages. Of note, we found that UUO kidney $\Phi$-IL-4/IL-13 macrophages lost their M2 phenotype and showed either the M1 or the M1 and M2 double positive transition phenotype. Thus, we demonstrate that nearly all $\Phi$-IL-4/IL-13 macrophages switch their canonical phenotype when localized into the UUO kidney. In addition to phenotype switching, transcriptional analysis confirmed that the infused $\Phi-\mathrm{IL}-4 / \mathrm{IL}-13$ macrophages switched to functional M1. Although our findings strongly suggest that those changes on $\Phi-\mathrm{IL}-4 / \mathrm{IL}-13$ were induced by the inflammatory milieu present in the UUO kidney, unfortunately we were not able to prove such hypothesis since the number of infused macrophages isolated from the contralateral normal kidney was too low to allow further characterization.

Matrix metalloproteinases (MMPs) were previously thought to be anti-fibrotic because of their ability to induce extracellular matrix remodeling. However, recent studies suggest that MMPs are involved in the initiation and progression of kidney fibrosis in chronic kidney disease [29]. The precise mechanism by which MMP-9 contributes to renal fibrosis still is a matter of debate. Our results agreed with those reported by Tan et al. suggesting that MMP-9 contributes to the pathogenesis of renal fibrosis via macrophage recruitment [30]. Furthermore, Harris and Wang [2] suggested that M1 macrophages induce renal fibrosis by MMP-9 secretion. In summary, the previous study on Adriamycin nephropathy showing functional switching of $\Phi-\mathrm{IL}-4 / \mathrm{IL}-13$ macrophages to M1 [12] and our study, extend current knowledge about macrophage plasticity in vivo by showing for a first time both phenotype and functional change of $\Phi$-IL-4/IL-13 macrophages isolated from the UUO kidney. 


\section{Cellular Physiology Cell Physiol Biochem 2017;42:1945-1960

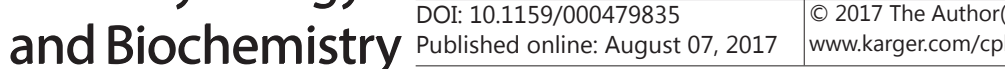

There are several approaches to overcome this significant limitation. One is provided by Cao et al. [12] by using spleen macrophages which show lower proliferative ability. Alternatively, we used in vitro stabilized NGAL macrophages. In agreement with the significant reduction of kidney fibrosis after $\phi$-NGAL therapy, we found that $\phi$-NGAL macrophages isolated from the UUO kidney displayed predominantly the M1-M2 double positive phenotype with a significantly higher proportion of macrophages with preserved M2 phenotype in comparison to the $\Phi-\mathrm{IL}-4 / \mathrm{IL}-13$ findings. Interestingly, the $\phi-\mathrm{NGAL}$ macrophages showed lower TGF- $\beta 1$ and TNF- $\alpha$ expression compared to the $\Phi$-IL-4/IL13 ones. Moreover, the $\phi$-NGAL macrophages isolated from the UUO kidneys showed high Wnt7b gene expression, consistent with their favorable phenotype [2]. Lin et al. [31] described that macrophages in response to renal injury produce and release the Wnt ligand Wnt7b that acts on injured tubular epithelial cells (TECS) to promote regeneration of the tubule basement membrane, thus re-establishing renal architecture and reducing renal fibrosis. $\Phi$-IL-4/IL-13 macrophages also express Wnt7b and Lcn2/NGAL genes but at low level, since they just did not get induced as high as the RAW 264.7 cells transduced with Lcn2/NGAL. Altogether, this data reveals that transformed macrophages were able to better preserve their antinflammatory and antifibrotic phenotype when were eventually located in the obstructed kidney.

Additionally, information of endogenous macrophages gene expression, although indirectly, may provide further evidence of the adoptive cell transfer effect. Therefore, $\phi$-NGAL therapy could modify the functionality of the endogenous macrophages in the obstructed kidney, as suggested by the reduction of some pro-inflammatory (TNF- $\alpha$ ) and pro-fibrotic (MMP-9 and TGF- $\beta 1$ ) genes in comparison to the endogenous macrophages from non-treated UUO mice.

Macrophage plasticity resulted in confusion regarding the identity of individual macrophage populations [32] although it is a critical feature of these cells to regulate the balance of renal injury, inflammation, repair and fibrosis [2,33]. Moreover, this plasticity is a major limitation to macrophage cell therapy. Infusion of $\Phi$-IL-4/IL-13 macrophages in the UUO model may act as adding fuel to the fire since more cells become M1 and thus amplifying renal inflammation and fibrosis. Understanding macrophage heterogeneity is critical because these cells can be biomarkers and have also the potential to be used as therapy. Therefore, more studies are needed before using this kind of therapy in humans [32].

There is one limitation in our study. RAW264.7 is a cell line derived from monocytic leukemic cell of BALB/c that carries H-2d whereas C57BL/ 6 carries H-2b. Adoptive transfer of cells to mouse with different $\mathrm{H}-2$ antigen is possibly immunogenic. The mice strain usually used to study chronic kidney damage is C57BL6 based on its susceptibility to renal fibrosis [34]. On the other hand, to achieve a stable $\phi$-NGAL transduction, we used the commercial cell line RAW264.7. Previous studies from our group and others [28, 35, 36], suggested that infusing these cells in the C57BL/6 is and even in other species was not immunogenic, at least in the short-term. In agreement with these experiences, we did not observe any effect related to the potential activation of an effector alloimmune response against the infused cells in our model, although we could not rule out that repeated infusions during a more prolonged follow up could be challenging. In conclusion, our study provides further evidence that macrophage plasticity is a critical limitation for macrophage cell therapy in CKD and shows that it can be partially overcome by inducing ex vivo stable and anti-fibrotic macrophage.

\section{Acknowledgments}

We thank Esther Castaño for her help with sorter analysis, Beatriz Barroso for her help with cytometer and Benjamín Torrejón for his help with confocal microscopy (Scientific and Technical Services, UB, Barcelona, Spain). We also thank to Núria Bolaños and Cristian Varela (IDIBELL, Barcelona, Spain) and Ângeles Muñoz (IIBB-CSIC-IDIBAPS) for their excellent 


\section{Cellular Physiology Cell Physiol Biochem 2017;42:1945-1960 \begin{tabular}{l|l|l} 
10.1159/000479835 & () 2017 The Author(s). Published by S. Karger AG, Basel
\end{tabular} and Biochemistry Published onlne: August 07, 2017 www.karger.com/cpb}

Guiteras et al.: Macrophage Transfer Reduces Chronic Kidney Damage

technical support.

This research was supported by Spanish Government Instituto de Salud Carlos III (ISCIII) grant PI12/01427, PI15/00638 and PI12/00720 Confunded by FEDER funds/ European Regional Development Fund (ERDF)-a way to Build Europe-//, AMGEN grant under the auspices of The Red de Investigación Renal (European Regional Development Funds ISCIII Red Temática de Investigación Cooperativa en Salud Red de Investigación Renal; RD16/0009/0003) and SENEFRO (awarded to AS). SAF 2015-67770 (awarded to GH). AS is supported by Miguel Servet contracting system (CP08/00138).

\section{Disclosure Statement}

All the authors declared no competing interests.

\section{References}

1 Zeisberg M, Neilson EG: Mechanisms of Tubulointerstitial Fibrosis. J Am Soc Nephrol 2010;21:1819-1834.

-2 Cao Q, Harris DCH, Wang Y: Macrophages in Kidney Injury, Inflammation, and Fibrosis. Physiology 2015;30:183-194.

-3 Ricardo SD, Goor H Van, Eddy AA: Science in medicine Macrophage diversity in renal injury and repair. J Clin Invest 2008;118:3522-3530.

4 Hung T-W, Tsai J-P, Lin S-H, Lee C-H, Hsieh Y-H, Chang H-R: Pentraxin 3 Activates JNK Signaling and Regulates the Epithelial-To-Mesenchymal Transition in Renal Fibrosis. Cell Physiol Biochem 2016;40:1029_ 1038.

-5 Murray PJ: Macrophage Polarization. Annu Rev Physiol 2017;79:541-566.

6 Meng X-M, Nikolic-Paterson DJ, Lan HY: Inflammatory processes in renal fibrosis. Nat Rev Nephrol 2014;10:493-503.

7 Guiteras R, Flaquer M, Cruzado JM: Macrophage in chronic kidney disease. Clin Kidney J 2016;9:765-771.

8 Kitamoto K, Machida Y, Uchida J, Izumi Y, Shiota M, Nakao T, Iwao H, Yukimura T, Nakatani T, Miura K: Effects of liposome clodronate on renal leukocyte populations and renal fibrosis in murine obstructive nephropathy. J Pharmacol Sci 2009;111:285-292.

-9 Pan B, Liu G, Jiang Z, Zheng D: Regulation of renal fibrosis by macrophage polarization. Cell Physiol Biochem 2015;35:1062-1069.

10 Chazaud B: Macrophages: Supportive cells for tissue repair and regeneration. Immunobiology 2014;219:172-178.

-11 Huen SC, Cantley LG: Macrophage-mediated injury and repair after ischemic kidney injury. Pediatr Nephrol 2015;30:199-209.

12 Cao Q, Wang Y, Zheng D, Sun Y, Wang C, Wang XM, Lee VWS, Wang Y, Zheng G, Tan TK, Wang YM, Alexander SI, Harris DCH: Failed renoprotection by alternatively activated bone marrow macrophages is due to a proliferation-dependent phenotype switch in vivo. Kidney Int 2014;85:794-806.

13 Lo T-H, Tseng K-Y, Tsao W-S, Yang C-Y, Hsieh S-L, Chiu AW-H, Takai T, Mak TW, Tarng D-C, Chen N-J: TREM-1 regulates macrophage polarization in ureteral obstruction. Kidney Int 2014;86:1174-1186.

14 Wang Y, Wang YP, Zheng G, Lee VWS, Ouyang L, Chang DHH, Mahajan D, Coombs J, Wang YM, Alexander SI, Harris DCH: Ex vivo programmed macrophages ameliorate experimental chronic inflammatory renal disease. Kidney Int 2007;72:290-299.

15 Jung M, Sola A, Hughes J, Kluth DC, Vinuesa E, Viñas JL, Pérez-Ladaga A, Hotter G: Infusion of IL-10expressing cells protects against renal ischemia through induction of lipocalin-2. Kidney Int 2012;81:969982.

16 Flaquer M, Franquesa M, Vidal A, Bolaños N, Torras J, Lloberas N, Herrero-Fresneda I, Grinyó JM, Cruzado JM: Hepatocyte growth factor gene therapy enhances infiltration of macrophages and may induce kidney repair in db/db mice as a model of diabetes. Diabetologia 2012;55:2059-2068.

17 Jung M, Brüne B, Hotter G, Sola A: Macrophage-derived Lipocalin-2 contributes to ischemic resistance mechanisms by protecting from renal injury. Sci Rep 2016;6:21950. 


\section{Cellular Physiology Cell Physiol Biochem 2017;42:1945-1960 \begin{tabular}{ll|l} 
10.1159/000479835 & ( ) 2017 The Author(s). Published by S. Karger AG, Basel
\end{tabular} and Biochemistry Published onlne: August 07, 2017 www.karger.com/cpb}

Guiteras et al.: Macrophage Transfer Reduces Chronic Kidney Damage

18 Halloran F, Racusen LC, Solez K, Broecker V, Cosio F, Demetris AJ: Banff ' 09 Meeting Report : Antibody Mediated Graft Deterioration and Implementation of Banff Working Groups 2010;10:464-471.

-19 Hutchinson JA, Riquelme P, Sawitzki B, Tomiuk S, Miqueu P, Zuhayra M, Oberg HH, Pascher A, Lützen U, Janssen U, Broichhausen C, Renders L, Thaiss F, Scheuermann E, Henze E, Volk H-D, Chatenoud L, Lechler RI, Wood KJ, Kabelitz D, Schlitt HJ, Geissler EK, Fändrich F: Cutting Edge: Immunological consequences and trafficking of human regulatory macrophages administered to renal transplant recipients. J Immunol 2011;187:2072-2078.

20 Wise AF, Williams TM, Kiewiet MBG, Payne NL, Siatskas C, Samuel CS, Ricardo SD: Human mesenchymal stem cells alter macrophage phenotype and promote regeneration via homing to the kidney following ischemia/reperfusion injury. Am J Physiol Renal Physiol 2014;306:F1222-1235.

21 Zhao J, Wang L, Cao A-L, Jiang M-Q, Chen X, Wang Y, Wang YM, Wang H, Zhang X-M, Peng W: HuangQi Decoction Ameliorates Renal Fibrosis via TGF- $\beta$ /Smad Signaling Pathway In Vivo and In Vitro. Cell Physiol Biochem 2016;38:1761-1774.

-22 Jiang MQ, Wang L, Cao A, Zhao J, Chen X, Wang Y, Wang H, Peng W: HuangQi Decoction Improves Renal Tubulointerstitial Fibrosis in Mice by Inhibiting the Up-Regulation of Wnt/ $\beta$-Catenin Signaling Pathway. Cell Physiol Biochem 2015;36:655-669.

23 Feger M, Alesutan I, Castor T, Mia S, Musculus K, Voelkl J, Lang F: Inhibitory effect of NH4Cl treatment on renal Tgfß1 signaling following unilateral ureteral obstruction. Cell Physiol Biochem 2015;37:955-964.

-24 Xu MJ, Feng D, Wang H, Guan Y, Yan X, Gao B: IL-22 ameliorates renal ischemia-reperfusion injury by targeting proximal tubule epithelium. J Am Soc Nephrol 2014;25:967-977.

25 Thirabanjasak D, Tantiwongse K, Thorner PS: Angiomyeloproliferative lesions following autologous stem cell therapy. J Am Soc Nephrol 2010;21:1218-1222.

-26 Todorova D, Kim J, Hamzeinejad S, He J, Xu Y: Brief Report: Immune Microenvironment Determines the Immunogenicity of Induced Pluripotent Stem Cell Derivatives. Stem Cells 2016;34:510-515.

27 Kim M-G, Kim SC, Ko YS, Lee HY, Jo S-K, Cho W: The Role of M2 Macrophages in the Progression of Chronic Kidney Disease following Acute Kidney Injury. PLoS One 2015;10:e0143961.

28 Sola A, Weigert A, Jung M, Vinuesa E, Brecht K, Weis N, Brüne B, Borregaard N, Hotter G: Sphingosine-1phosphate signalling induces the production of Lcn-2 by macrophages to promote kidney regeneration. J Pathol 2011;225:597-608.

29 Zhao H, Dong Y, Tian X, Tan TK, Liu Z, Zhao Y, Zhang Y, Harris DC, Zheng G: Matrix metalloproteinases contribute to kidney fibrosis in chronic kidney diseases. World J Nephrol 2013;2:84-89.

30 Tan TK, Zheng G, Hsu T-T, Lee SR, Zhang J, Zhao Y, Tian X, Wang Y, Wang YM, Cao Q, Wang Y, Lee VWS, Wang C, Zheng D, Alexander SI, Thompson E, Harris DCH: Matrix metalloproteinase-9 of tubular and macrophage origin contributes to the pathogenesis of renal fibrosis via macrophage recruitment through osteopontin cleavage. Lab Invest 2013;93:434-449.

- 31 Lin S-L, Li B, Rao S, Yeo E-J, Hudson TE, Nowlin BT, Pei H, Chen L, Zheng JJ, Carroll TJ, Pollard JW, McMahon AP, Lang RA, Duffield JS: Macrophage Wnt7b is critical for kidney repair and regeneration. Proc Natl Acad Sci USA 2010;107:4194-4199.

- 32 Mosser DM, Edwards JP: Exploring the full spectrum of macrophage activation. Nat Rev Immunol 2008;8:958-969.

33 Ma W, Tao L, Wang X, Liu Q Zhang W, Li Q, He C, Xue D, Zhang J, Liu C: Sorafenib Inhibits Renal Fibrosis Induced by Unilateral Ureteral Obstruction via Inhibition of Macrophage Infiltration. Cell Physiol Biochem 2016;39:1837-1849.

34 Walkin L, Herrick SE, Summers A, Brenchley PE, Hoff CM, Korstanje R, Margetts PJ: The role of mouse strain differences in the susceptibility to fibrosis: a systematic review. Fibrogenesis Tissue Repair 2013;6:18.

-35 Gerasimovskaya E, Kratzer A, Sidiakova A, Salys J, Zamora M, Taraseviciene-Stewart L: Interplay of macrophages and T cells in the lung vasculature. Am J Physiol Lung Cell Mol Physiol 2012;302:L10141022.

- 36 He Z, Dursun B, Oh D-J, Lu L, Faubel S, Edelstein CL: Macrophages are not the source of injurious interleukin-18 in ischemic acute kidney injury in mice. Am J Physiol Renal Physiol 2009;296:F535-F542. 